\title{
Sanctuary islands in a hostile matrix: the perception, representation, and protection of the Flower Garden Banks National Marine Sanctuary, Gulf of Mexico
}

\author{
Philip Hayward \\ University of Technology Sydney \\ prhshima@gmail.com
}

\begin{abstract}
The Flower Garden Banks (FGBs), located in the Gulf of Mexico due south of the Texas-Louisiana border, are protrusive, ocean-floor diapirs. These features, which occur widely around the Gulf's coastal plains and continental shelf, are caused by dome-shaped extrusions of salt deposits into the strata above them. The FGBs are distinct and merit analysis on account of the peculiarity of their fate in the Anthropocene Era in a region that has been heavily exploited and impacted by both offshore oil-drilling and by commercial and recreational fishing. Unlike many other diapirs, the FGBs have benefitted from perception, identification, and characterisation as distinct islands (in the biogeographical sense of the term), and from their successful nomination as a US National Marine Sanctuary (NMS). This article reflects on these aspects with regard to the nature of and criteria informing the US Act that enabled the creation of NMSs; the key concept of 'sanctuaries' involved; and the manner in which the FGBs have been conceived, protected, and represented under the Act. Attention is also accorded to the manner in which the FGBs have been represented in various media and how this effectively creates them for the general public. Drawing on these discussions, the article identifies both the complexity involved in conceptualising a submarine space as an NMS and the fragility of such sanctuaries in the late Anthropocene and, more specifically, during a period of political turmoil within the nation-state that established them.
\end{abstract}

Keywords: Flower Garden Banks, National Marine Sanctuaries, representation, salt domes, seafloor features

https://doi.org/10.24043/isj.89 • Received December 2018, accepted May 2019

(C) 2019-Institute of Island Studies, University of Prince Edward Island, Canada.

\section{Introduction}

Diapirs are geological features caused by upwellings of salt that cause dome-shaped distortions in the strata above them. When these occur close to the surface they often protrude above flat areas of land or, if located beneath the sea, appear as seamounts. One aspect of diapirs that has been key to their experience during the Anthropocene era is their concentration of valuable mineral resources (namely salt and oil) in their upper portions, facilitating relatively easy extraction via excavation and/or drilling. The pursuit of such extractions without proper safeguarding and/or remediation activities has led to a variety of damage to hollowed-out 
diapirs, including subsidence on the crest of their domes, internal collapses, and-for terrestrial domes such as Louisiana's five (so-called) "land islands"- -damage caused by ground water seepage or, on occasion, rapid inundation from surrounding watercourses" (see Hayward \& Moore, 2018). This experience typifies what Pugh (2018, p. 93, p. 97) has termed "the shifting stakes of the Anthropocene" that have delivered "dynamically interweaving spatial relations."
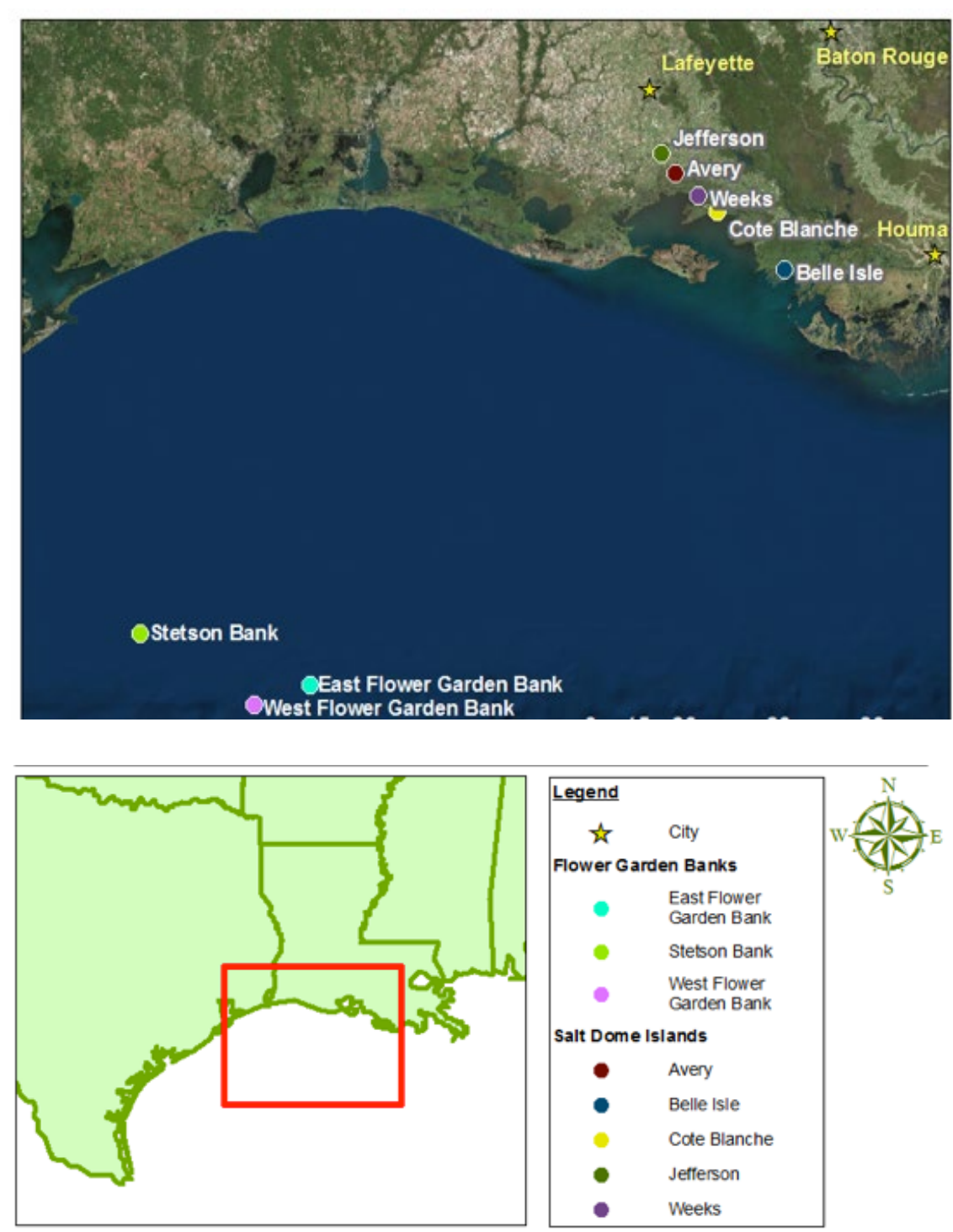

Figure 1: Location of the Flower Garden Banks, Stetson Bank, Louisiana's five terrestrial salt dome islands (Jefferson, Avery, Weeks, Cote Blanche, and Belle) and adjacent cities. Source: Alahna Michele Moore, 2017.

The domes discussed in this article, the East and West Flower Garden Banks (FGBs), are located 87 miles (140 kilometres) south of the Texas coast, on the floor of the Gulf of Mexico (Figure 1). This article analyses the perception and management of these seafloor features drawing on frameworks developed by Hawkins (2018) with regard to geopolitical discourses accruing to Ferdinandea/Graham Island (a volcanic island that briefly rose above the surface of the Mediterranean, southwest of Sicily, in 1831). Noting that "subterranean and submarine spaces often attract attention in part through their resistance to or complication 
of regimes of visualisation," Hawkins (2018, p. 1) emphasises the need for an aesthetic approach to the "regimes of visualisation involved" that actively "enables a complication of thinking around how it is we know subterranean spaces, their dimensions, dynamics and materialities, all features important to their geopolitical significance." Like her discussion, this article also points to the manner in which such analyses contribute to "recent geopolitical engagements with the complexities of the volumetric and the vertical, of terrain and territory, and the geopolitical and geophysical" (Hawkins, 2018, p. 1). As Hawkins (2018, p. 6) succinctly states, one of the key challenges for aesthetic and epistemological inquiry is "how exactly it is that we can come to know these spaces, and hence render them legible and controllable."

In addition to the visually oriented framework and discussions offered by Hawkins, this article considers the terminologies used to refer to subaquatic features, examines the wording of US legislation concerning them, and the extent to which concepts of 'flowers' and 'gardens' have been crucial to perceptions of the FGBs' space, place, and significance (in contrast to those of the [oil] 'fields' that surround them). This discussion, in turn, leads to a recognition of the limited security and effectivity of marine reserves with specific regard to the nature of the 'sanctuary' invoked in their designation as NMSs. The article thereby investigates how we conceive of aquatic spaces and/or habitat islands through representation. In mounting this analysis, the article draws on the interrelated concepts of shima and the aquapelago to examine NMSs in general and the FGB NMS in particular, and points to the usefulness of the two concepts for wider research on and conceptualisation of oceanic environments in the Anthropocene. Similarly, the case study of the FGBs contributes to an understanding of such features as existing within highly compromised local-level contexts. Through these considerations, the article addresses questions of scale and of the complexity of terrestrialoceanic relations in the Anthropocene which are significant for humans seeking to intervene in them for preventive and/or remedial purposes.

\section{The Flower Garden Banks: location, structures and human discovery}

Salt domes and associated cap rocks and sedimentary rock hosts provide one of the most diverse economic entities of any geologic feature. (Posey \& Kyle, 1988 p. 8)

There are estimated to be over 500 diapirs of various sizes and elevations protruding from the seafloor on the continental shelf around the Gulf of Mexico (an arc that extends from Mexico's Yucatan peninsula, in the south, to Florida, in the northwest) (Marine Conservation Organisation, n.d.), together with a number of larger, sub-surface formations known as salt massifs (Posey \& Kyle, 1988). Salt strata formations around the coast and on its adjacent continental shelf have been widely drilled for oil over the last century and the discovery of protrusive salt dome formations on the seafloor has often been accompanied by densely clustered offshore drilling operations (Figure 2). Along with indicating the likely presence of oil reserves below their caps, protrusive submarine diapirs have also attracted human attention by providing raised areas that facilitate clusters of distinct aquatic vegetation, coral, fish, and crustaceans. The elevated formations constitute biogeographical entities of a type referred to by Whittaker and Fernandez-Palacios (2007, p. 11) as "marine habitat islands" within an otherwise "hostile matrix." The "matrix" referred to by the latter is that of the surrounding terrain and environments but may, in the context of this article, also be extended 
to refer to the "hostile matrix" constituted by both intrusive fisheries and industrial oil extraction operations across the Gulf.

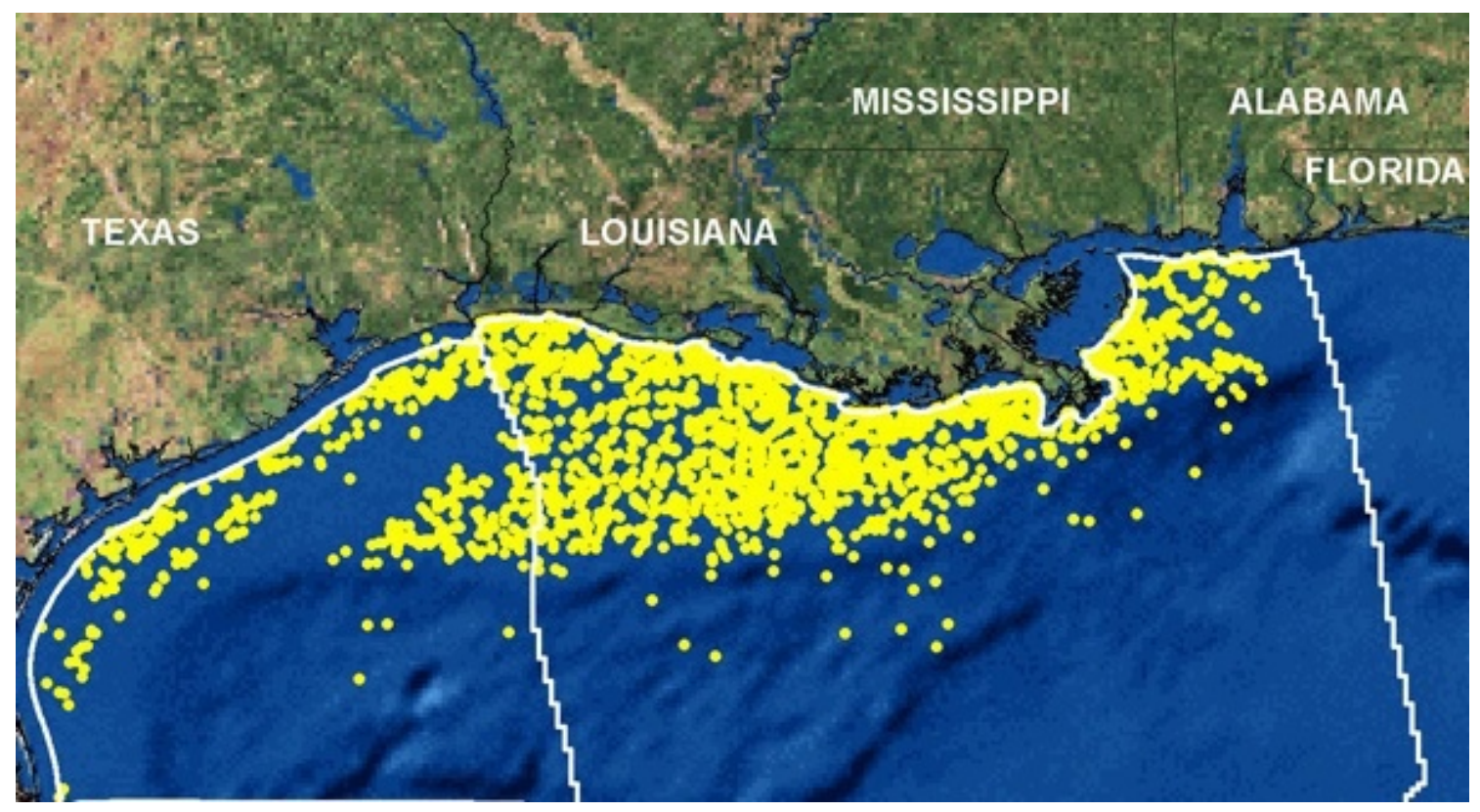

Figure 2: Locations of oil drilling operations along the Texas-Alabama Coast (showing borders of the Western and Central planning areas aligned to Texas-Louisiana and AlabamaFlorida state borders). Source: Jack Kisslinger, planetforlife.com, 2010.

The East and West FGBs, together with a third elevated area, Stetson Bank (which has been associated with the former two through designated protection measures), occur within a dense cluster of diapirs located off the coastline between Texas and northwestern Florida. Despite the prolonged history of habitation of the Gulf Coast region (dating back to the late Pleistocene Era), and the presence of coastal peoples around the coast of the (present-day) states of Texas and Louisiana at the time of European 'discovery', invasion, and settlement in the 1500s, there is no evidence of any social awareness of the seafloor features discussed in this article prior to the mid- $20^{\text {th }}$ century. This, in itself, does not establish a lack of prior knowledge of the features by previous inhabitants of the region, but, similarly, there is no evidence that pre-European coastal populations fished as far as 200 kilometres offshore, let alone in the area in which the FGBs are located. In this sense, the FGBs' alleged 'discovery' by US snapper and grouper fishermen in the late 1800s-albeit through the proxy of the availability of clusters of fish not present elsewhere in the deep waters off the continental shelf-may be an actual one (in human terms at least).

The mapping of seafloor features in the Gulf of Mexico is largely a $20^{\text {th }}$ - and $21^{\text {st }}$-century phenomenon that has been undertaken by survey vessels of various kinds using a range of depth-measuring technologies. The FGBs are located on an area of continental shelf that gently declines from a depth of 100 metres, to the FGBs' immediate north, to 120 metres, to their immediate south. The coral-covered peaks of the FGBs rise to around 40 metres below the ocean surface, crowning masses that cover seafloor areas of c55 square kilometres (West Bank) and c75 square kilometres (East). While fishermen appear to have known that an area of sea in the vicinity hosted grouper and snapper usually found in shallower waters from the late $1800 \mathrm{~s}$ 
on, the FGBs were only identified and named in the early 1900s. At this time, fishermen established their existence and named them after the vividly coloured corals that lay close to the surface on their peaks, samples of which were occasionally dragged up in fishing nets (NOAA, 2001). The terminology they used is significant. The word 'flowers'-rarely used by marine botanists (at least, with regard to subaquatic plants) — can be seen as a favourably analogous characterisation of coral to terrestrial plants. Similarly, the term 'garden' is analogous-but in a more complex manner. Its everyday usage refers to an area in which decorative or food plants are cultivated, but the term also has a prominent Biblical association in the form of the Old Testament's Garden of Eden. The latter has two primary associations, first as a bucolic locale amply blessed with fruits of all kinds, and, second, as an ideal space irretrievably violated by human folly in breaching prohibitions on their use of the space. Adding to these associations, the term 'garden' also has a distinct meaning in American English, referring to a large bounded recreational space (such as New York's Madison Square Garden arena) (Pollack, 2010). As subsequent discussions will elaborate, the aggregation of these conceptual aspects in the FGBs' name is far from incidental to their subsequent imagination, representation, and elaboration. Note, for instance, the National Oceanic and Atmospheric Administration and Sea Turtle Conservancy's joint project webpage (NOAA, 2001). After comparing diapirs to "underwater gardens," the page describes FGBs as "like oases in the desert," a characterisation that is simultaneously vivid (emphasising their biological richness), biogeographically apposite and also evocative of various Biblical oases (such as Elim, featured in Exodus 15:27). The banks' name and related characterisations provide them with an enduring associative 'charge' which informs perception and discussion of them in a manner that, for instance, the names of other Gulf banks-such as Geyer, Rankin, or Sonnier-do not.

Knowledge of the FGBs appears to have remained limited for much of the early- to mid-20 $0^{\text {th }}$ century. The US Navy and American Society for Oceanography conducted surveys around the FGBs in 1968, mapping their shape and the topography of the seafloor around them through depth-sensing technologies. As Hawkins (2018, p. 22) has identified, our current perception and mapping of such features differs from traditional cartography in that the former "has been premised on seeing" whereas subsurface oceanic features are comprehended and represented through "multisensory" media. Noting that "many visualisations of the sea bed are actually formed through data produced by practices of sounding," she reflects that "what emerges," within a geo-strategic framework, "is a need for more multisensory ways of knowing as part of how we both understand and mobilise volumetric practices of power." With regard to Hawkins' discussions, it is worth reiterating that the first perception of the existence of the FGBs was produced by proxy, in the form of fish clustered around particular points in the sea that suggested the existence of subsurface peaks. This is a significant point. The fish inhabited a space around the banks that was dependent/contingent on them but was different in substance, mass, and character from them. The colourful coral fragments that were dredged up were more closely aligned to the materiality of the banks-in that they grew upon them-but were, nevertheless, different in form from the banks themselves and, therefore, can be considered just as much a proxy of the FGBs' existence as the fish were. So, from their earliest recognition by humans, the FGBs were cognitively "brought into being" through a convergence of indicators, and were geomorphic formations substantially defined by the plant and coral types that adhered to their upper surfaces and of the fish that swam around them. 
In these ways - and particularly through their linguistic designation as gardens-the FGBs are as much rhetorical constructs as they are material entities.

In her discussion of the detection, perception, and representation of the short-lived manifestation of Ferdinandea/Graham Island in 1831, Hawkins (2018) refers to the concept of the aquapelago: an assemblage of marine and terrestrial spaces generated by human livelihood activities (Hayward, 2012). Describing the aquapelago as "a land-oceanic continuum that when mobilised requires that we resist any easy distinction between the subterranean and submarine" (Hawkins, 2018, p. 3), she contends that the concept problematises "politicolegal concepts of territory" (Hawkins, 2018, p. 10) premised on notions of fixed terrestrial spaces. The concept/figure of the aquapelago is equally apposite in terms of the FGBs' comprehension and representation by human agencies and to the subsequent eco- and geopolitical discourses, strategies, and legislative measures passed to restrict human use of its subsurface spaces, since it emphasises the FGBs and NMSs as entities performed by an intersection of animate and inanimate objects and the abstract discourses applied to them.

Prior to European settlement and $20^{\text {th }}$-century development of the shore and hinterlands of the Gulf of Mexico, the waters off its immediate coast supported a rich biomass that was a significant resource for the coastal populations that harvested various organisms in its coastal shallows. Various types of marine vessels, fishing gear, and harvesting techniques introduced by European settlers extended the scale and extent of the fisheries and created a close involvement of coastal populations with in-shore waters. From the late 1940s on, this offshore activity was accompanied by another, the extraction of oil from offshore deposits located in salt strata around the continental shelf. It is notable, with regard to the discussions advanced in this article, that the term used to refer to both terrestrial and seafloor subsurface oil deposits is 'field'. This term derives from the Old English term feld, which originally referred to a tract of open land and was later used to refer to "a parcel of land marked off and used for pasture or tillage" (Etymology Online, n.d.). The term subsequently became extended to more specific areas, such as 'sports fields' in the late 1800s (Etymology Online, n.d.). The first use of the term 'oil field' appears to have been around the 1860s (Merriam Webster, n.d.) following the development of commercial extraction processes in Pennsylvania. The date of the first use of the term to describe offshore oil deposits is unclear but appears to have followed the development of sites in the Gulf of Mexico in the late 1940s. But whereas the harvesting of planted fields involves the cyclic gathering of a renewable bioresource that is maintained by humans for that purpose, the extraction of oil is more accurately a (one-off) draining and transfer of a pre-existent geomorphologic resource without remediation of the local environment. In this sense, the use of the term 'field' by the oil industry can be seen as a cosmetic one that masks the face of one activity with a term appropriated from another context. For much of human history, agriculture has been (and has been regarded as) a livelihood activity integrated with various aspects of the natural world-with humans being one aspect of the multi-species terrestrial assemblages involved in the activity in a relatively sustainable manner. Oil extraction, by contrast, has been conducted in subsurface strata in manners that have exemplified Anthropocene degradation of the seafloor, oceanic chemistry, and related biomasses.

The Gulf's offshore oil industry is premised on maritime rig technologies: metal structures connected to the seafloor which support the insertion of drill heads into the salt 
strata and the subsequent extraction of oil to the surface via pipes. This activity, and the related transfer of oil to ships and/or piping to hub facilities for transit to onshore processing facilities, has involved multiple disruptions of the seafloor and incidental operational pollution of seawater. But while this has had an adverse impact on the marine environment, a greater concern has been the increasing pollution of Gulf waters by fertiliser run-off from onshore agribusiness operations that have seeped into the Mississippi and its tributaries. This runoff is deposited into the ocean via the Mississippi Delta, creating a hypoxic (i.e., oxygen-depleted) zone just above the seafloor which extends for around 15,500 square kilometres around the shore of the Gulf. While the pollution spikes and subsides in an annual cycle, dependent on patterns of application of fertilisers, its peak periods massively diminish demersal (i.e., bottomdwelling) fish and shellfish stocks in a continuing cycle that impedes breeding and causes “dead zones" (Diaz \& Rosenberg, 2008).

In 2010, the catastrophic condition discussed above was compounded by the most sudden, intensive, and most visibly perceptible pollution event caused by the offshore oil industry to date: the massive spillage of oil from the offshore Deepwater Horizon (DH) rig. DH was conducting exploratory drilling in 1,600 metres of water in the Macondo prospect zone, some 66 kilometres off the southeastern Louisiana coast (within the offshore oil drilling areas identified in Figure 2). The DH spillage was triggered by a rapid upflow of methane gas from the subsurface salt strata to the drillhead platform, where it ignited in an explosion that severely damaged its wellhead in a manner that allowed the oil deposit to gush unimpeded into the ocean from the drill bore. This forceful leakage injected around 780,000 cubic metres of oil into the Gulf (Flow Rate Technical Group, 2010) in the form of both surface slicks and submarine plumes, causing both immediate and short- to medium-term fatalities in bird, marine mammal, and demersal fish and shellfish species in the Gulf and along adjacent shorelines (Wallace et al, 2017).

As should be evident, the inadvertently engineered injection of a large volume of viscous fluid into the saline hydrology of the Gulf during the DH incident proceeded without reference to any legislated (or otherwise assumed) spatial delineations of 'protected' areas of the Gulf and/or its ocean floor. This aspect is particularly pertinent with regard to the following aspect of this article's discussion of the FGBs, their designation as an NMS.

\section{National Marine Sanctuaries}

NMSs are distinct from terrestrial environmental reserves in that the latter are almost exclusively defined by borderlines that demark particular land areas from their surrounds (and do not attempt to delineate areas of airspace above them or, with few exceptions, subterranean spaces beneath them). NMSs, by contrast, operate as demarcated areas that comprise the volumes of water that occupy the spaces between cartographic reference points and include the seafloors of these areas. Such 'sanctuaries' are usually associated with waters around islands or coastal locations or else located above shallow features (such as sub-surface plateaux, seamounts, reefs, etc.) that support marine species that are effectively tethered to the submarine features and their shallows.

The US National Marine Sanctuary System was created under Title III of the 'US Marine Protection, Research, and Sanctuaries Act' (1972) (henceforth referred to as 'the Act') (NMS, 2015). The use of the term 'sanctuaries' in this context merits attention. The first 
significant aspect is that the latter is not one of the thirteen terms defined in the preamble to the Act (despite its obvious significance as one of the three key terms in its title). In everyday usage the term 'sanctuary' has three principal meanings (the latter of which derive from the former). Etymologically, the term derives from the Latin word sanctus, meaning holy, with sanctuary referring to a holy site, such as a consecrated Christian place of worship of the type that has allowed fugitives of various types to 'seek sanctuary'-i.e., safe (if largely temporary) domicile-within them. This usage, in turn, resulted in the term being used more generally to refer to spaces created under various ordinances that offered safe domicile to other species threatened by humans (and/or other species), giving us the concept of the 'wildlife sanctuary'. While it would seem apposite to understand the use of the term 'sanctuary' in the US Act primarily in the latter sense, it is not inappropriate to also perceive it to be imbued by a spiritual sense of holiness transposed to a secular context (in terms of environmental values). But there are also more complex levels at work in the ascription of sanctuary status to assemblages of animate and inanimate elements. Humans and human perceptions and values play a key role here, both as co-creators of such assemblages and as objectifiers of them. While his development of these concepts has been hitherto little remarked upon by scholars, a number of publications by Japanese anthropologist and Island Studies theorist Jun'ichiro Suwa are particularly pertinent for the above considerations.

Suwa's initial work on the concept of shima, particularly as it is understood in Japan's Amami Islands, identified the manner in which a term that is usually translated into English as 'island' is far more nuanced, embodying a dual meaning: "islands as geographical features and islands as small-scale social groups where cultural interactions are densely intermeshed" (Suwa, 2007, p. 6). As Suwa elaborates, in traditional Amami culture, each shima is "enacted through various practices and performances of demarcation" and is "a work of territorial imagination, an extension of personhood and a "cultural landscape" (Suwa, 2007, p. 6).

In this sense, he contends:

a shima is a sanctuary, in that the natural environment and social space are articulated in such a way that one imagines them as a totality... Territory is thereby strongly associated with the livelihood of communal social spaces and a particular type of territorial imagination, for its boundary consists of landmarks. Waters, coastlines and hills mark shima; the territories are imagined and created as a place... produced through boundary marking ravines, reefs, or hills, providing resources for imagination and the drawing of lines and shapes on landscapes. (Suwa, 2007, p. 6)

In a subsequent article that discusses the compatibility of concepts of shima with the previously discussed concept of the aquapelago, he contends that:

One of the possible ways of grasping the nature of aquapelagic assemblages might be to focus on locations where fractal concentric circles initiate activities. This point might be regarded as a 'sanctuary', using an expanded definition of that term that includes its complementary characterisations of a holy/spiritual centre, a place of refuge and safety and a reserve where flora and fauna are protected. (Suwa, 2012, p. 14) 
Noting his indebtedness to Akimichi's (2004) concept of kami no commons (which derives from the type of sanctuary offered by Shinto shrines), Suwa contends that:

Aquapelagic assemblages can be conceived as sanctuaries with regard to either real or imagined space... Key to the imagination of sanctuary is a shared idea that constructs cultural reality and thereby becomes crucial to any such project. Sanctuary therefore is a type of spatio-temporal space where things take place, operate and interact within a particular framework... Aquapelagic assemblages-and/or the sanctuaries they comprise-are not necessarily self-contained, self-sufficient and/or self-sustainable. They are not bounded, ahistorical 'utopias' [of] the stereotypical 'idyllic' or 'pastoral' landscape... Aquapelagic assemblages are, rather, specific products of ongoing processes in actual locations... [As] sanctuaries manifested in land/seascapes, they are occupied with sacred, untouchable, memorised and/or identified elements that are shared through and as common knowledge, skill, consciousness, desire and ideology. (Suwa, 2012, pp. 14-15)

This sophisticated characterisation is entirely apposite to the discussion of NMSs in general and the FGBs NMS in particular. Indeed, Suwa's contention summarises a set of perceptions that illuminate the concept of sanctuary embodied with the Act (and its subsequent modifications), various assertions of it, and the rationales for attempts to gain NMS status for particular locations. My assertion of this in no way suggests that the authors of the Act consciously conceptualised NMSs in such manners but, rather, that the framework of the Act and the various clauses that create NMSs as legislated entities involve a similar process of recognition-and-becoming that Suwa ascribes as an organic aspect of human imagination and management of space.

While the original 'US Marine Protection, Research, and Sanctuaries' Act, passed in 1972, addressed the establishment of NMSs as something of an afterthought to its primary focus on regulating the dumping of harmful materials in coastal waters (in its Clauses I-II); Title IIIa Finding 2 of the modified version of the Act passed by Congress in 1984 contained a significant expansion of the factors that might lead to designation of an area as an NMS, identifying that:

certain areas of the marine environment possess conservation, recreational, ecological, historical, scientific, educational, cultural, archeological, or esthetic qualities which give them special national, and in some cases international, significance. (US Government, 1972)

Title IIIa Finding 4 identified that the Federal program established by the Act aimed to:

(A) improve the conservation, understanding, management, and wise and sustainable use of marine resources;

(B) enhance public awareness, understanding, and appreciation of the marine environment; and

(C) maintain for future generations the habitat, and ecological services, of the natural assemblage of living resources that inhabit these areas (US Government, 1972). 
The identification of a number of human activities and perceptions as providing national and international "significance" to specific marine environment sites and the reference to "natural assemblages" appears to imply an interface between the two that creates an implicit recognition of the aquapelagic nature of the sites, i.e., their establishment as nationally significant as a result of aquapelagic interactions around them and perceptions of them. Rather than simply authorising the establishment of aquatic wilderness zones in which non-human biota can be preserved with minimal human intervention, the Act explicitly emphasised both the nature of particular marine areas as shima (in the sense elaborated by Suwa above) and their aquapelagic aspects (and the ability for these to be maintained) as key aspects of the designation of NMSs. While such designation (to date) precludes commercial fishing and blocks oil prospecting and extraction within sanctuary boundaries, socioeconomic concerns such as recreation (including recreational fishing) and tourism have always been pivotal to the designation.

Before moving to examine individual NMS sites designated under the Act, it is worth returning to the principal purpose of the first iteration of the Act: i.e., to minimise dumping in and related pollution of US marine areas. While the provisions of the Act had some impact on industrial practices, the extent and impact of the DH oil spill in the Gulf of Mexico in 2010 demonstrated that existing protections and penalties were woefully inadequate. Responding to research into industry practices, President Barack Obama established the Bureau of Safety and Environmental Enforcement in 2016 to monitor and enforce new guidelines on oil industry operational safety at a level never previously seen in the US. This enterprise was, however, short-lived. Shortly after gaining office in 2017, President Donald Trump signed an executive order entitled 'The America First Energy Strategy', began winding back the Bureau's powers, and handed much of the control back to (predominantly Republican controlled) states in which the oil lobby exercises significant influence.

\section{Designated sites}

The first NMS was established in 1976, four years after the Act was passed (with the responsibility for approval having shifted from the Secretary of Commerce to the President in the interim). The first sanctuary was a maritime heritage site designated by President Gerald Ford with somewhat loose adherence to the provisions of the first iteration of the Act (being an area off the North Carolina coast where the sunken Civil War era ship the USS Monitor had been discovered in 1972). A second site approved by Ford later that year was of a significantly different type. The Key Largo NMS was established to protect the only living coral barrier reef on the US East Coast, which was-and remains-a major dive attraction for tourists. Florida's nomination of the site was an early indication of the state's intent to maintain and develop its offshore waters for tourism purposes (in marked contrast to its systematic devastation of its Everglades swamp system [see Grunwald, 2007]). This intent also led the state to prohibit offshore oil drilling through various measures in the following decades, including, most recently, a statewide ban approved in a state referendum held in association with the US mid-term primaries in November 2018.

The replacement of Republican President Ford by Democrat Jimmy Carter in 1977 led to a new impetus for establishing NMSs with the Department of Commerce's National Oceanic and Atmospheric Administration (NOAA) drawing up a list of 67 potential candidate areas. Carter went on to authorise the establishment of four NMSs, around California's 
Channel Islands (1980) and California's Point-Reyes Farallon Islands, Florida's Looe Key, and Georgia's Gray's Reef (all in 1981). Following a period of inactivity during the first four years of Ronald Reagan's presidency, NOAA was successful in gaining approval for the establishment of an NMS in Fagatale Bay in American Samoa in 1985. Further NMSs were approved off the Florida and California coasts in 1989-1990, following President George Bush's inauguration, before a 13-year-long campaign to have the FGBs designated succeeded in 1992. In 1996 the nearby Stetson Bank, a "sandstone bank with fire coral and sponge-covered pinnacles and flats" (NOAA, n.d.), was added to the FGB NMS, with the three being jointly administered and represented by NOAA's National Ocean Service (Figure 3). NOAA has identified the FGB NMSs" "key habitats" as "sand flats, soft sediments, bank reefs, drowned reefs, pinnacles, hard substrate [...] algal sponge communities, brine seeps/flows, fault scarps, and artificial reefs" and has identified significant species as including "star coral, brain coral, manta rays, hammerhead sharks, and endangered loggerhead sea turtles" (NOAA, n.d.). These, together with the various humans who visit and/or otherwise engage with the area through its representations, can be considered to constitute the FGBs NMS's general aquapelagic assemblage.

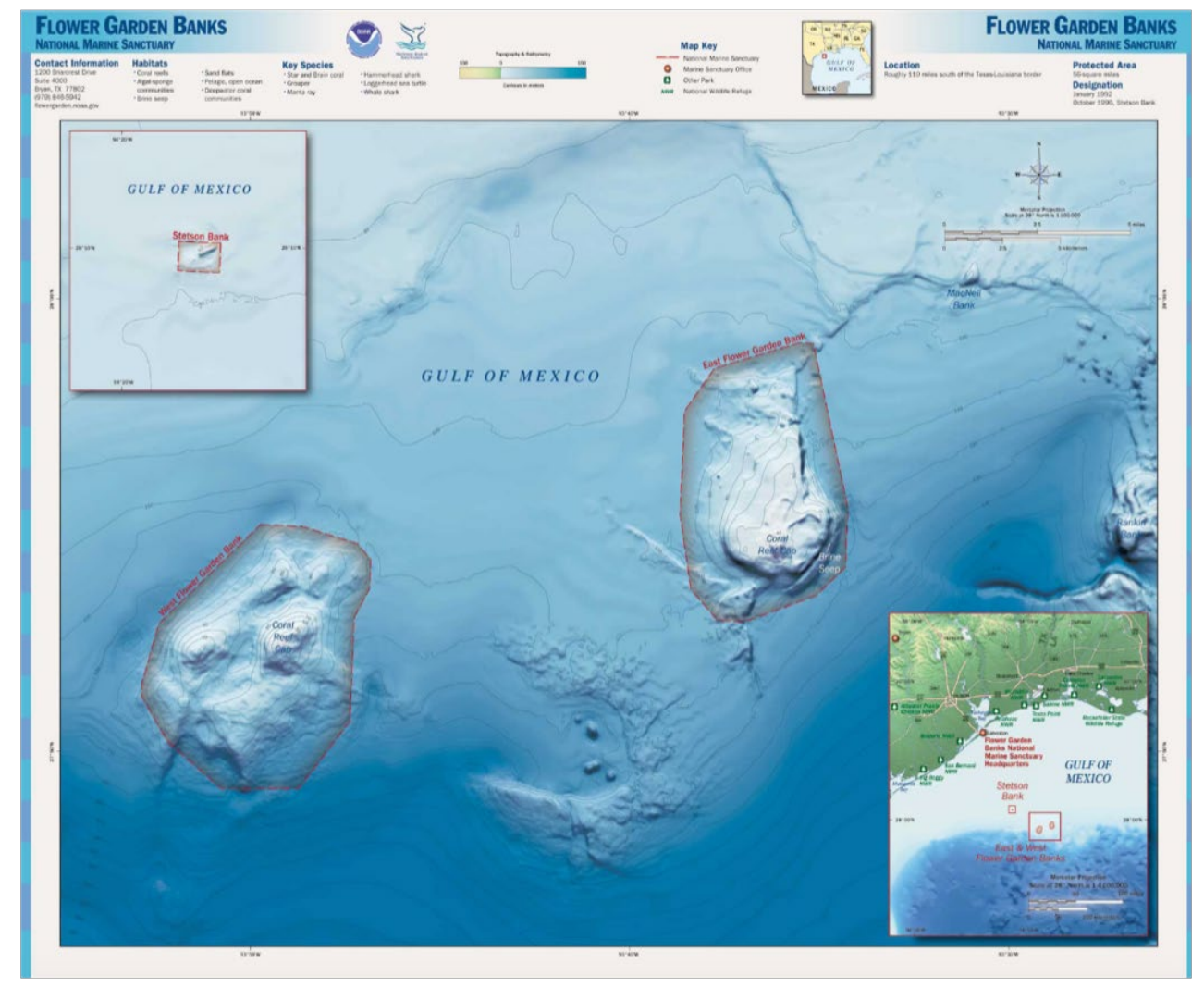

Figure 3: Map of the Flower Garden Banks National Maritime Sanctuary (delineated by red perimeter lines), with inset showing position of Stetson Bank. Source: NOAA/public domain (n.d).

As entities located a considerable distance from the coast and at depths not visible to surface explorers using glass-bottomed boats, snorkels, etc., the raised seafloor features and the flora and fauna congregating around them are currently only directly accessible to those divers who can arrange their transport offshore and dive down to them wearing breathing apparatus. More generally, the FGBs are principally manifest to and apprehensible by the 
public through their representation via media products on NOAA's website pages devoted to the FGBs NMS. These include a series of maps, including the most commonly used image (Figure 3), and a webpage devoted to the FGBs. The (five-episode) Sanctuary Video Series (NOAA, 2001) also gives viewers lovingly assembled 'diver's-eye' perspectives on the colourful marine life on and around the Banks in a manner that derives from Jacques Cousteau's pioneering documentaries in the 1950s and persists in contemporary dive documentaries. As Mikkola (2018) emphasises, such productions have an important function within the 'popular imaginary', providing us with the type of "encounter with inaccessible environments" that we need in order "to be able to care" for them (2018, p. 5; my emphasis). In this manner, the audiovisual representations of the FGBs produced by NOAA can be perceived as PR devices utilised to build affective alliances with members of the public who, with few exceptions, will never actually dive down to the Banks and experience their beauty and biological richness firsthand. Such public relations activity is a crucial aspect of NOAA's management of and advocacy for NMSs. Public interest in and support for the continued protection and designation of NMSs cannot be taken for granted, but must, rather, be nurtured in order for politicians to perceive such support and to take that into account in their responses to competing commercial and political agendas.

In the manner outlined above, the FGBs exist in overlapping planes. They exist as entities that are apparent through proxy indicators (fish, coral, etc.) that are spatially appraised and visually rendered through depth-sensing technologies and are represented in audiovisual media deployed by divers. They also exist as the focal components of a legislated entity that delineates and articulates the space around them as an NMS. The FGB NMS is, thereby, a representative spatial instantiation of the legislative-rhetorical discourse and prohibition mechanisms of the NMS program (embodying all the complexities of the latter) as much as it is a place with an objective existence.

\section{Conclusion}

Commencing with discussions about the conception and nomenclature of 'islandish' spaces on the seafloor, this article's discussions have sought to engage with Pugh's (2018, p. 99) apposite and timely observation that "thinking about islands in terms of multiple, unfolding temporalities and the richness of relationality in the Anthropocene raises some new questions for island ontology" and, in particular, his attempts to push the bounds of 'relationality' of islands into consideration of "TARDIS-like" spaces (Morton, 2016) where totalities are "greater than anything which can be experienced phenomenologically" (Pugh, 2018 p. 100). The maps, website, and video representations of the FGBs' subaquatic flora and fauna, and ongoing data gathering on biota, water conditions, etc., by NOAA, are assembled and displayed to assert, manifest, and inform the maintenance of the FGBs NMS as a defended entity. In this regard, they typify - in micro-what Springer and Turpin (2017, p. 18) refer to as the "morphology of sovereignty," which increasingly "exhibits" itself through "dematerializations, virtualizations, physical reassertions, and material instantiations." The FGB NMS might thereby be seen to project and aspire to a relational 'micro-sovereignty' within the 'hostile matrix' of the Gulf of Mexico that is as rhetorical as the micronational statuses that have been asserted for various islands and offshore platforms in various locations over the last century (Shima, 2014-). Located within the globally integrated space and 
immediate temporality of the Anthropocene, and immersed in a liquid environment that cannot support any protective membrane other than the highly permeable and fragile provisions of national legislation, the FGBs' sanctuaries resemble Ferdinandea/Graham island, as discussed by Hawkins (2018). They have risen and been subject to claims and contestation at a particular historical juncture and are as fragile in temporal terms as they are in environmental ones. In particular, the fragility of environmental regulations in Trump-era USA gives little cause for optimism. Just as aquapelagos, in general, 'wax and wane' as climate and environmental conditions and related human uses of space alter (Hayward, 2012), so, too, does the effectivity of the protection of marine areas prescribed by sovereign governments at particular historical moments. Sanctuary, whilst precious, is usually fleeting.

The discussions advanced in this article have sought to convey the complex nature of ecological protectionism in oceanic contexts by identifying the complex nature of aquapelagic spaces (such as the FGBs) and of designated marine ecological reserves (such as the FGB NMS). Rather than being segmented geographical locations, both can be understood to be assemblages articulated within various types of discourse and characterised by concepts and representations derived from preconstituted cultural tropes. The identification and acknowledgement of such discourses in operation thereby serves to emphasise the highly complex nature of any attempts to deflect or 'unravel' the unfolding of the Anthropocene with regard to specific situations and locales.

\section{Acknowledgements}

Preliminary research for this article was conducted as part of a visiting research fellowship at the Midlo Center for New Orleans Studies at The University of New Orleans in 2016. Thanks to Connie Zeanah Atkinson from the Midlo Center for facilitating the initial development of this project; to Kelly Drinnen from NOAA for assisting with my research inquiries in 2017-2018; to Alahna Michele Moore for her research assistance and mapping skills; to Jun'ichiro Suwa for both inspiring many lines of thought and for providing feedback on an earlier draft; and to Amelia Coyle-Hayward and the anonymous ISJ referees who provided an incisive critique of my initial submission to the journal. Both the initial version of this article and its final revision were undertaken in the convivial environment of the University of Hong Kong; thanks to Otto Heim for facilitating this.

\section{References}

Akimichi, T. (2004). Commons no jinruigaku. Tokyo: Jinbun Shoin.

Diaz, R.J., \& Rosenberg, R. (2008). Spreading dead zones and consequences for marine ecosystems. Science, 321(5891), 926-929. https://doi.org/10.1126/science.1156401

Etymology Online (n.d.). Field. https://www.etymonline.com/word/field

Flow Rate Technical Group (2011). Assessment of flow rates estimates for the Deepwater Horizon/Macondo Well oil spill. National Incident Command, Interagency Solutions Group.

Grunwald, M. (2007). The Swamp: The Everglades, Florida and the politics of paradise. New York: Simon and Schuster.

Hayward, P. (2012). Aquapelagos and aquapelagic assemblages. Shima, 6(1), 1-10. 
Hawkins, H. (2018). 'A Volcanic Incident': Towards a geopolitical aesthetics of the subterranean. Geopolitics, 24(3), 1-26. https://doi.org/10.1080/14650045.2017.1399877

Hayward, P., \& Moore, A.M. (2018). Vertical features in flux: elevation, interiority and the Anthropocene disruption of South West Louisiana's five salt dome land islands. Journal of Marine and Island Cultures, 7(2), 37-45. https://doi.org/10.21463/jmic.2018.07.2.02

Merriam Webster (n.d.). Oil field. $\underline{\text { https:/www.merriam- }}$
webster.com/dictionary/oil\%20field

Mikkola, H. (2018). Movements beyond human: Ecological aesthetics and knowledges in underwater wildlife documentaries. Finnish Journal for Human-Animal Studies, 4, 4-26. https://doi.org/10.23984/fjhas.59505

Morton, T. (2016). Molten Entities. In D. Daou \& P. Pérez-Ramos (eds.). New Geographies 8: Island (pp. 72-76). Cambridge: Universal Wilde.

National Marine Sanctuaries (2015). National Marine Sanctuaries historical timeline. https://doi.org/10.5670/oceanog.2003.13

National Oceanic and Atmospheric Administration (NOAA) (2001). Flower Garden Banks National Marine Sanctuary profile. https://doi.org/10.5962/bhl.title.11363

National Oceanic and Atmospheric Administration (NOAA) (n.d). Sanctuary Video series. https://flowergarden.noaa.gov/image library/videoseries.html

Pollack, M. (2010). Why is Madison Square Garden called a garden? Was it ever a garden? New York Times, 9 July. https://www.nytimes.com/2010/07/11/nyregion/11fyi.html

Posey, H., \& Kyle, R. (1988). Fluid-Rock interactions in the salt dome environment: An introduction and review. Chemical Geology, 74, 1-24. https://doi.org/10.1016/0009_ 2541(88)90143-x

Pugh, J. (2018). Relationality and island studies in the Anthropocene. Island Studies Journal, 13(2), 93-110. https://doi.org/10.24043/isj.48

Shima (2014-). Anthology on Islands and Micronationality. Shima. https://doi.org/10.21463/shima.im.anth.int

Springer, A.S., \& Turpin, E. (2017). The Science of letters. In A.S. Springer \& E. Turpin (eds.). Reverse hallucinations in the archipelago (Intercalations \#3) (pp. 1-52). Berlin: SYNAPSE-The International Curators' Network, K. Verlag \& Haus der Kulturen der Welt.

Suwa, J. (2007). The space of shima. Shima, 1(1), 1-14.

Suwa, J. (2012). Shima and aquapelagic assemblages: a commentary from Japan. Shima, 6(1), 12-16.

United States Government (1972). US Marine Protection, Research, and Sanctuaries Act. https://web.archive.org/web/20120508220037/http://www.epa.gov/aboutepa/histo ry/topics/mprsa/

Wallace, B.P., Brosnan, T., McLamb, D., et al. (2017). Effects of the Deepwater Horizon oil spill on protected marine species. Endangered Species, 33, 1-7.

Whittaker, R., \& Fernandez-Palacios, J.M. (Eds.) (2007). Island Biogeography: ecology, evolution and conservation. Oxford: Oxford University Press. 